\title{
E-GOVERNMENT IN BULGARIA - STRATEGIC OBJECTIVES FOR DEVELOPMENT AND RESULTS FROM IMPLEMENTATION OF PROJECTS
}

\author{
T. Daskalova* \\ University of National and World Economy, Sofia, Bulgaria
}

\begin{abstract}
The development of e-Government is the main priority in the strategic documents of the Republic of Bulgaria during the programme period 2014-2020. The projects financed under Operational Programme "Good Governance" are of key significance both for the attainment of the strategic objectives and of the expected results input in them. The purpose of the publication is to analyse the conformity between the strategic documents and the projects implemented in the sphere of e-Government in the country. A desk analysis, an empirical analysis and other scientific methods are applied for the attainment of the purpose in the research. Problems in their development are identified as a result of the analysis of the current projects and alternatives are proposed for their elimination. Perspectives are outlined for the future development of the e-Government in Bulgaria in conclusion.
\end{abstract}

Key words: Strategy, operational programme, e-Government projects

\section{INTRODUCTION}

During the programme period (2014-2020) the Government of the Republic of Bulgaria defines the accelerated development of the electronic government (e-Government) as one of its main priorities. National strategic documents are adopted, directed at the building up of information infrastructure for provision of electronic services for the citizens and the business, digital transformation of the administration, introduction of complex administrative servicing and so on. Operational Programme "Good Governance" (OPGG) is the main instrument for the attainment of the strategic objectives in the sphere of eGovernment. The Programme finances strategic projects of key central administrations for the development of the e-Government in the public sector.

The subject-matter of the research are the projects implemented under Priority Axis 1 „Administrative Servicing and e-Government" of OPGG for the period from the month of

\footnotetext{
Correspondence to: Tatyana Daskalova, University of National and World Economy, Sofia 1700, tel. +35928195 621, e-mail: tdaskalova@unwe.bg
}

February 2015 (approval of the Programme by the European Commission) up to the month of May 2019. The purpose of this research is to evaluate the contribution of the projects for the attainment of the input objectives and priorities in the strategic and programme documents in the sphere of e-Government. Main problems were outlined as a consequence of the analysis of the progress in the implementation of the projects at their realization. Specific author's proposals were made for their overcoming in this respect.

The thesis is defended that the successful implementation of the priority projects under OPGG has a key contribution for the future development of the e-Government in the country.

\section{STRATEGIC FRAMEWORK OF THE ELECTRONIC GOVERNMENT IN BULGARIA}

The main instrument for realization of projects in the sphere of the e-Government for this programme period at a national level is OPGG, directed at modernization of the state administration through the improvement of the quality of servicing of all the groups in the society [1]. It unites Operational Programme 
"Administrative Capacity" and Operational Programme "Technical Assistance" from the preceding programme period (2007-2013). Most initiatives and projects with regard to the system for e-Government at a state and at a local level were supported by Operational Programme "Administrative Capacity". The focus was placed onto one of its axes - Priority Axis 3 "Administrative Servicing of Quality and Development of Electronic Government", which aims at the improvement of the quality of the administrative services in Bulgaria and the introduction of the e-Government. OPGG builds upon the interventions under these two Operational Programmes and renders assistance to the building up of information systems and electronic services for introduction of administrative servicing in an electronic manner.

The support under OPGG is directed at the improvement of the quality of the administrative services and the access to them, reduction of the administrative burden, introduction of instruments and procedures for surveillance and assessment of the public policies and so on. In this connection the strategy of OPGG is built up on the improvement of the functioning of the state institutions for the attainment of these objectives. Strategic (horizontal) priority 4 "Good Governance and Access to Administrative Services of Quality (inclusive of development of e-Government and eJustice)" of the Partnership Agreement [2], which outlines the assistance from the funds of the European Union (EU) for the period 20142020 , is implemented through the Programme. OPGG is directly bound to the attainment of the objectives of Priority 6 "Strengthening the institutional environment for higher efficiency of the public services for citizens and businesses" of the National Development Programme "Bulgaria 2020"[3]. It is the main instrument providing the connection between the national priorities of Bulgaria with the objectives of the EU within the context of the strategy "Europe 2020". The Programme renders assistance to the realization of the objectives through a wide package of measures for development of e-Government in the public sector: reduction and gradual elimination of the complicated procedures for provision of services, reduction of the administrative burden in selected spheres of priority, expansion of the application of the information and communication technologies, introduction of the complex administrative services and expansion of the electronic services of the administrations for the citizens and the business as well as for the enhancement of the transparency of the public sector.

Strategy on the Development of e-Government in the Republic of Bulgaria 2014-2020 [4] was adopted in this respect. It is a main national strategic document, which aims at generalization and building upon preceding documents in this sphere, providing the vision for development of e-Government in the public sector of Bulgaria. Three strategic objectives are input in it - provision of qualitative, efficient and easily accessible electronic services for the citizens and the business; transformation of the administration into digital administration through integration of the information processes; popularization, access and participation. Their attainment is additionally guaranteed by the adopted in parallel Road Map for Implementation of the Strategy on the Development of e-Government in the Republic of Bulgaria 2016-2020 [5]. It includes a multitude of measures and activities for the realization of the strategic objectives input in the strategy, the institutions responsible for that as well as the amount of the needed financial resource for realization of projects related to upgrading and improvement of the main electronic resources of eGovernment.

Several more strategic documents were adopted further to them which represent natural continuation of the E-Governance Development Strategy and form its sector security - Strategy for Introduction of eGovernance and e-Justice in the Justice Sector 2014-2020, sector strategy "E-Customs" 20162020 and the Road Maps for their implementation [6].

The Public Administration Development Strategy (2014-2020) was also developed in support of the institutional priority of the National Programme for Development of the country [7]. One of its main aspects refers to the more efficient use of the limited resources for provision of public services of quality.

The Bulgarian institutions unambiguously declare in the national strategic documents applied during the present programme period the improvement of the e-Government as a mandatory condition for the conduct of good governance as their main objective. 
ACHIEVED PROGRESS IN IMPLEMENTATION OF PROJECTS FOR E-GOVERNMENT

Priority Axis 1 (PA 1) "Administrative Servicing and e-Government" of OPGG has two specific objectives:

- Reduction of the administrative and regulatory burden for the citizens and the business and introduction of the principles of "episodes of life" and "business events".

- Increase of the services accessible for the citizens and the business rendered in an electronic manner.

For the attainment of the objectives for each calendar year the Management Body of OPGG develops indicative annual working programmes for the forthcoming procedures for provision of grants. The dynamics of implementation and negotiation results in variations in the annual programmes for all the years: for 2015, 2016 and 2017 the programmes have two variations, for 2018 three variations, for 2019 - one variation. The procedures change and new ones are added, by which to guarantee the better attainment of the objectives of the Programme. The selection of a type of a procedure is conformed to their specifics, objectives, their convexity with strategic documents and legislative requirements and the relevant responsibilities of the administrations.

Strategic projects for key central administrations are financed under PA 1 , directed at reforming the model for provision of administrative services, mitigation or removal of regimes, register reform, completion of the central systems of the electronic government and so on. 11 nos. of procedures were announced during the period 2015-2019 in execution of PA 1, including 42 measures which are related both to the administrative reform and to the development of e-government. The beneficiaries are 20 central administrations, inclusive of: the Council of Ministers; 8 Ministries; 4 Executive Agencies; 3 state agencies; 3 national agencies and institutes, 1 State Commission. The Administration of the Ombudsman of the Republic of Bulgaria and the National Association of the Municipalities in the Republic of Bulgaria are included.

The projects implemented under PA 1 with regard to orientation may be systematized in the following groups:

- Projects for structuring data and analytical activities in execution of the strategic documents for the development of the state administration, development of the electronic government and the introduction of the electronic government into Sector "Justice". The main activities for the performance of stocktaking of the information and communication infrastructure, the information arrays and the registers used, as well as standardization and unification of the processes at the provision of administrative services, definition of specific measures for improvement of the legislation. The purposes of the projects are to provide sustainable impact, efficiency and transparent prioritization of the future interventions in the indicated spheres.

- Projects of priority in execution of the Road Map for implementation of the Strategy on the Development of e-Government in the Republic of Bulgaria (2016-2020). They have direct contribution to the building up or updating of existing registers, information systems, portals and platforms and provision of integration between them, as well as of operational compatibility with platforms of the EU. Further to the development of eGovernment in its wide scope, a part of the projects is directed at the development of the sector systems of e-government, amongst which e-health care, e-taxes, e-customs and estatistics are.

- Projects for improvement of the effectiveness, the efficiency and the transparency of the system for public procurements, which directly contribute to the attainment of some of the objectives of the National Strategy for the Development of the Public Procurement Sector in Bulgaria (20142020). The main activities are addressed at the reduction of the administrative burden for award of public procurements as well as creation of prerequisites for greater publicity and transparency of the system and building up administrative capacity within the sector. The result of the implementation of these activities is the development of a unified national webbased platform.

- Strategic projects for implementation of the State Administration Development Strategy (2014-2020). The projects of horizontal nature predominate in this group, directed at the application of the policies and the principles of good governance - building up capacity for application and assessment of the impact of policies, creation of unified rules for conduct of functional analyses of horizontal and sector policies, creation of models for optimization of administrative structures and 
so on. The remaining projects are directed at the creation of a portal for open data and a platform for access to public information. The objective of these projects is the overall improvement of the processes related to the provision, the access and the repeated use of the information from the public sector.

- Projects related to upgrading and development of a state hybrid private cloud, upgrading of the horizontal and central systems of e-government, upgrading of main systems and registers of central administrations for provision of data and electronic services. The projects contribute both to the electronization of the services rendered by the administrations to the citizens and the business and to passing to complex administrative servicing.

The following generalizations may be made with regard to the technical implementation of the projects. Under PA 1 as of 31.05.2019 there are 30 projects approved, of which 1 project was completed during the month of February 2018 and 29 projects are in the process of implementation. The realization of the projects is in a different phase of progress depending on the initial date of the project or the date of the conclusion of the Contract.

The current projects under PA 1 correspond to the objectives and the priorities of OPGG. The projects have clearly defined connexity with the main strategic documents, inclusive of with measures and activities from the road maps to them. This preserves the strategic focus of the procedures and directly contributes to the attainment of the objectives if PA 1 and the strategies. A set of projects of priority for financing under OPGG is anticipated in the strategic documents. The State Administration Development Strategy (2014-2020) includes 35 interventions within the framework of 17 measures and the Strategy on the Development of e-Government in the Republic of Bulgaria (2014-2020) - 30 measures in 13 spheres of priority. The projects implemented during the period 2015-2019 address a significant part of the measures anticipated for financing under OPGG in the strategic documents: State Administration Development Strategy - 69\%, E-Government Development Strategy - 83\%; the National Development Programme "Bulgaria 2020" - 58\%; Updated Strategy for Reform in the Judiciary $-50 \%$. All the projects under PA 1 are in implementation of the objective for development of electronic services and overall improvement of the administrative servicing, which is expected to create better conditions for business and efficient use of the resources.

The financial plan of PA 1 for programme period 2014-2020 adds up to 271,8 million BGN or $41,59 \%$ of the total budget of OPGG. For the analysed period the agreed funds are at the value of 184,2 million BGN or $67,77 \%$ of the budget of PA 1 .

The submitted requests for payment add up in total to 77 nos., inclusive of: advance - 27 nos., interim -49 nos., final -1 no. The really paid funds add up to 51,81 million BGN or $28,13 \%$. As a result of the analysis of the current projects under PA 1 according to data of the annual reports on the implementation of OPGG problems are established related to their development.

With regard to the preparation of the projects difficulties are observed pertaining to some beneficiaries. The absence of specific technical expertise in the sphere of the information technologies is a reason for submission of project proposals, which are not sufficiently well prepared aimed at their realization being possible directly after the signing of the Contract. This imposes the development of a great part of the Technical Terms of Reference by external contractors which results in delay of the preparation of the projects. Big delays are generated in some of the projects also due to the long periods of coordination of the technical documentation inside the administrations or with other administrations. Delays in the implementation varying from 2-3 months to 15-18 months are observed in a significant part of the projects. The slow preparation of the procedures for award of public procurements, which takes of the time planned for the realization of the projects is the main problem for nearly all the projects. Difficulties are established related also to the appeal with regard to some procurements of the decisions of the Contracting Authorities which additionally results in the extension of the term for implementation of the projects.

In some projects there are no prerequisites for realization of their results related to need of amendments in the legislation or existence of appropriate technical environment as information systems, portals and registers.

Difficulties are also established at the reporting of the projects related most of all to the great in volume reporting documentation at the development of annual and final reports by the beneficiaries. The information collected by the 
beneficiaries about the implemented project activities and results achieved in the monitoring system may not be presented in a generalized kind for the purposes of the assessments of the projects.

Other reasons for the problems at the realization of the current projects are: delay in the formation and the organization of the work of the teams; absence of motivation in some of the teams; weak ownership over some of the projects; absence of timely support by key stakeholders.

There are also external factors exerting impact over the progress of the projects. During the period 2015-2019 the statutory environment which OPGG is implemented in, is dynamic. A multitude of amendments are made in the national legislation as well as new acts are adopted, the road maps for execution of strategic documents are updated. Institutional changes are also made as, for instance, structuring of the State E-Government Agency as a successor of Executive Agency "Electronic Communication Networks and Information Systems". The associated mechanism for surveillance over the execution of the strategic documents in the sphere of the administrative reforms and e-Government is insufficiently efficient.

Some specific proposals for overcoming the identified problems may be made as a consequence of the analysis conducted, to wit:

- Improvement of the capacity of the beneficiaries with regard to the development of the concept of the projects for e-Government. The use of the methodology for development and introduction of public electronic services in the practice is appropriate for the purpose, uniting methods for: determination of the main actions for planning and organization of the development of the electronic service; creation of a project and realization of the service; determination of the parameters of introduction [8]. This will improve the quality of planning of the projects and the development of the technical specifications.

- Improvement of the possibilities for application of specialized software means designated for management of the projects, which are characterized by documentary complexity [9]. This is a prerequisite for adequate and timely management of the funds under the projects and reduction of the administrative burden.
- Creation of an independent Internet site of OPGG for facilitation of the access to the Programme. As of this time the information about the Programme is published on the Unified Information Portal of the European Structural and Investment Funds. Reflection on the Internet site of OPGG of various campaigns of the Management Body and analyses of publications related to the implementation of the Programme [10] are useful for the satisfaction of the needs of the beneficiaries of OPGG. Publication of clarifications with regard to frequently asked questions, encountered difficulties with the beneficiaries and good practices for solution of various cases and difficulties at the implementation of the projects is also useful with a view to overcoming the problems in the development of the projects.

\section{CONCLUSION}

The progress in this programme period in Bulgaria is related to the introduced strategic framework and the measures taken for development of e-Government. It is established as a result of the analysis that elimination of problems established in the implementation of the projects in this sphere is needed and application of specific actions for their successful realization which confirms the research thesis.

During the next programme period (20212027) the strategic intentions for the development of e-Government in Bulgaria are within the sphere of final building up of the needed information-communication infrastructure, connection of key registers and provision of operational compatibility for passing to automated exchange of data and electronic documents, technological solutions for provision of the administrative services on the basis of the complex administrative servicing, introduction of a national scheme for electronic identification, use of the horizontal systems and the shared resources of eGovernment, digital transformation of the administration, high level of information security, transformation of the data into information and knowledge and accomplishment of trust in the citizens and the business.

Priorities in these spheres are already being realized through projects under OPGG, and their successful implementation will have a key contribution to the future development of e-Government in the country. This will allow 


\section{DASKALOVA T.}

for synchronization and updating of the achieved up to date in the sphere of eGovernment, taking into consideration also the declared readiness on the part of the Bulgarian Government for the development of an Operational Programme for Electronic Governance during the next programme period.

\section{REFERENCES}

1. https://www.eufunds.bg/bg/opgg/node/83 Operational Program "Administrative Capacity"

2. https://www.eufunds.bg/bg/taxonomy/term/ 607 - Partnership Agreement

3. http://www.strategy.bg/StrategicDocuments /View.aspx?Id=765 National Development Program "Bulgaria 2020"

4. https://www.strategy.bg/StrategicDocument s/View.aspx ?lang=bg-BG\&Id=892

Strategy on the Development of eGovernment in the Republic of Bulgaria 2014-2020
5. https://www.strategy.bg/Publications/View.as px?lang $=$ bgBG\&categoryId $=\& I d=203 \& y=\&$ $m=-$ Road Map for Implementation of the Strategy on the Development of eGovernment in the Republic of Bulgaria 2016-2020

6. https://www.strategy.bg/StrategicDocuments/ View.aspx?lang=bg-BG\&Id=892 - Portal for Public Consultations

7. https://www.strategy.bg/StrategicDocuments/ View.aspx?lang=bg-BG\&Id=891 - Public Administration Development Strategy (20142020)

8. Kirilova, K., Methodological Issues in Development of Public Electronic Services, Economic and Social Alternatives, Issue 2, pp 84-98, 2016, ISSN 1314-6556.

9. Kirilov, R., Software Solutions for Managing Projects co-financed under the European Union's Operational Programmes, Business Management, Issue 3, pp 50-68, 2016, ISSN 0861-6604.

10. Milev, P., Opportunities for Implementing Internet Monitoring in Public Organizations, Economic and Social Alternatives, Issue 2, pp 58-69, 2018, ISSN 1314-6556. 